\title{
The Implications of Managed-Workforce Diversity on Internal Supply Chain Integration and Business Performance
}

\author{
Samuel Bruce Rockson ${ }^{1}$, Jonathan Annan ${ }^{2} \&$ Abdul Samed Muntaka ${ }^{2}$ \\ ${ }^{1}$ Dept. of Purchasing and Supply, Cape Coast Technical University, Cape Coast, Ghana \\ ${ }^{2}$ Dept. of Supply Chain and Information Systems, Kwame Nkrumah University of Science and Technology, \\ Kumasi, Ghana \\ Correspondence: Abdul Samed Muntaka, Dept. of Supply Chain and Information Systems, Kwame Nkrumah \\ University of Science and Technology, Kumasi, Ghana. E-mail: abusamgh@yahoo.com
}

Received: February 26, 2017

Accepted: March 28, 2017

Online Published: April 27, 2017

doi:10.5539/ijbm.v12n5p104

URL: https://doi.org/10.5539/ijbm.v12n5p104

\begin{abstract}
Today, workforce diversity management appears to attract strategic attention globally. Given this, a critical question that emerging research seeks to address is: is it even worth managing diverse workforce? Partly, this study addresses this question by examining the implications of managed-workforce diversity (MWD) on internal supply chain (SC) integration and business performance. Data was collected from one hundred and twenty six respondents using mainly questionnaires. The constructs employed to measure managed-workforce diversity, internal supply chain integration and business performance were together subjected to ANOVA, exploratory factor analysis (EFA) and then confirmatory factor analysis (CFA) and Structural Equation Model (SEM) in LISREL 8.5. Analysis of the data gathered indicated that MWD is most likely to be beneficial in enhancing internal SC integration and then SC responsiveness; with the former benefit acting as a conduit through which the latter benefit is experienced. The study therefore argues that effective workforce diversity management is one that creates and maintains MWD (which is a positive affective climate where employees do not feel intimidated, looked down upon, or discriminated against just because of background differences), all of which are necessary for driving internal SC integration, SC responsiveness, and financial outcomes. The managerial implications and the theoretical relevance of the study's findings are discussed in details.
\end{abstract}

Keywords: Workforce diversity management; Managed-workforce diversity; Internal supply chain integration, Supply chain responsiveness; Financial performance.

\section{Introduction}

Given that peopleare key resource of any organization and a dominating factor in its design (Mullins, 2010), managers are often confronted with challenges regarding how to recruit and combine the best set of people skills and maintain workforce balance so as to enhance performance. The difficulty often comes from the fact that employees possess varied abilities and have diverse inherent and explicit characteristics as well as different needs and expectations (Bedi, Lakra, \& Gupta, 2014; Bogaert \& Vloeberghs, 2005). As a growing concern, organizations are supposed to indiscriminately bring on board workforce with these differences and harness them to their advantage (Singal \& Gerde, 2015; Charted Instituted of Purchasing and Supply [CIPS], 2009). In this sense, effectively managing diverse workforce has become the way forward (Point \& Singh, 2003).

Although the concept of diversity and its discussions dates far back, increasing globalization, migration and consumer groups, talent shortage, and campaigns from pressure groups and governments have made it popular today (Bedi et al., 2014; Podsiadlowskia et al., 2013; Henry \& Evans, 2007; Keil et al., 2007; Bogaert \& Vloeberghs, 2005; Jayne \& Dipboye, 2004). Accordingly, not only is workforce diversity regarded today as a legal or governmental requirement, but it has also gained corporate and strategic considerations in many organizations across the globe (Bedi et al., 2014; Jayne \& Dipboye, 2004). It has been recognized that diversity sounds ethical and a reasonable basis for organizations to be socially responsible (Jayne \& Dipboye, 2004; Point \& Singh, 2003). Also, the search for finest talent and the increasing diverse customer groups require firms to embrace workforce diversity in order to effectively handle their consumer market (Podsiadlowski et al., 2013; Konrad, 2003). It is also argued that diversity brings out creativity and innovation and it enhances group-problem solving capabilities, increases productivity, value creation and ends up increasing firm 
competitiveness and performance (Bedi et al., 2014; Konrad, 2003).

Whereas much research attention has been on examining the above assertions (Bogaert \& Vloeberghs, 2005), there has not been much studies within the supply chain (SC) literature concerning the management and the implications of workforce diversity on SC practices and performance within and across firms. Not only are few conceptual discussions on workforce diversity within the SC literature but also, there is insufficient empirical attention on how workforce diversity management could become a source of capability for SCs. Even at the focal firm level, most diversity studies have focused on the micro-level (individual), with few focusing on the macro-level (organizational) or inter-organizational-level (Singal \& Gerde, 2015). Despite the emerging stream of studies on diversity at the upstream portion of the SC (i.e. supplier diversity), Richard et al. (2015) noted that there is still inadequate theoretical guidance and empirical findings concerning the impact of diversity on performance. Against this, and also the persisting inconsistent research findings, one could hardly claim that diversity certainly enhances business performance (Jayne \& Dipboye, 2004).

As a way forward, concerns relating to when does diversity become beneficial (Richard et al., 2015) and what mechanisms drive performance outcomes of diversity? (De Jong \& van Houten, 2014) have been raised. Also, there have been calls for exploring the effect of diversity in different business contexts (Kaufmann \& Wagner, 2017; Richard et al., 2015). Beyond these, we still believe that research that focuses on whether (or not) having a diversified workforce, or suppliers, or customers is beneficial without considering the management aspects of it leaves more work to be done. Bogaert and Vloeberghs (2005) noted that many organizations might lose sight and only focus on the inflow of diverse workforce as they may feel compelled to pay attention to workforce diversity which could result in them not being able to fully benefit from workforce diversity. In this sense, it is not just enough recognising diversity as an affirmative action, but also, taking a strategic lens towards its management is key, as implementing it could be challenging (Munjuri, 2012; Süß \& Kleiner, 2008). However, overcoming the challenges via effective management could allow firms to be more competitive (Bedi et al., 2014; Süß \& Kleiner, 2008).For practitioners, a critical question that still ought to be answered here is: is it even worth allocating scarce resources to manage workforce diversity? To partly address this question, this study focuses on and explores the implications of managed-workforce diversity (MWD, i.e. an organization-wide shared positive affective state where employees do not feel intimidated, looked down upon, or discriminated; an output of workforce diversity management)on internal SC integration, SC responsiveness, and firm financial performance.

The study relied on data from Ghana. Generally, research on workforce diversity issues in bottom-of-the-pyramid (BOP) countries is scanty. Along this, Singal and Gerde (2015) recommended that business contexts other than that of U.S., Canada, and U.K. where diversity issues are less salient should be explored. Ghana's unique institutional environment could largely shape specific workforce diversity management initiatives and outcomes. The results of this study will therefore provide guidance to practitioners in the research context and also offer theoretical inspirations for the broader academic environment.

\section{Conceptual Background}

\subsection{Workforce (Management) Diversity and Managed-Workforce Diversity}

The term diversity is a complex phenomenon. It embraces several definitions with varied meanings and contexts (Point \& Singh, 2003; Rosenzweig, 1998). According to Bedi et al. (2014), workforce diversity has to do with the similarities and differences in the characteristics of employees of an organization. Gee and Norton (1999) consider workforce diversity to mean "multiplicity of characteristics that distinguish one employee from another". Sources of workforce diversity include; but are not limited to: gender, age, race, heritage, ethnicity and/or culture, educational background, skills, physical (dis)abilities, values, beliefs, religion, sexual orientation, and personality and behavioural styles and attitudes (Munjuri, 2012; Bedi et al., 2014; Gee \& Norton, 1999). Workforce diversity management is "all about integrating the ideas and practice of diversity into the day-to-day managerial and learning processes of a company and its environment" (Keil et al., 2007). It is about how leaders or managers are able to institute programs and structures that "embrace all" (Jayne \& Dipboye, 2004), offer "opportunities to all" (CIPS, 2009), ensure "fair treatment" (Bedi et al., 2014), and promote "co-existence" (Henry \& Evans, 2007). Managing workforce diversity means creating a work environment that ensures the accommodation and acceptance of workforce without discrimination on the basis of their background differences (Jackson, Joshi, \& Erhardt, 2003).

Although most theoretical rationales that underpin the value of workplace diversity have focused on social identity and social categorization (Podsiadlowski et al., 2013). This study employs a strategic management perspective which does not only focus on embracing diversity because of any external pressure (legal and affirmative actions, e.g. recruiting and hiring workforce irrespective of their background differences) but also, 
geared towards recognising the strategic role of the concept workforce diversity (Munjuri, 2012; Süß \& Kleiner, 2008). Strategically, it is imperative for firms to appreciate the social and the psychological processes that characterize workforce diversity; the generation and the manifestations of inequality, discrimination, and prejudice at the workplace, their positive and negative consequences; and the role of structures and systems in creating an organization-wide process of managing workforce diversity so as to realize conducive work atmosphere, minimize dysfunctional results, and enhance firm competitive posture (Henry \& Evans, 2007; Munjuri, 2012; Bedi et al., 2014).

If organizations are successful in strategically managing diverse workforce, their workforce should be able to make sense of it. This leads us to the concept of managed-workforce diversity (MWD). Here, we clarify that MWD is not about 'what goes into' creating a diverse workforce or employees' but it is also about the perceptions the workforce or employees have about their organizations and the diversity programs in place. In other literature (Pugh et al., 2008; Gelfand et al., 2005; Madera, Dawson, \& Neal, 2013), the term 'diversity' has been used to illustrate the extent to which employees' perceive that their organization's diversity management (programs, policies, practices, and procedures) and managers' actions create, forester, and maintain diversity and eliminate discrimination. We contend that being able to recognize organization's diversity management efforts is one thing; and being able to actually experience the intended outcome of such efforts is another thing. It is about a perceived positive work atmosphere where the similarities and the differences of individuals are valued by all (Patrick \& Kumar, 2012). This study thus defines MWD as an organization-wide shared positive affective state where employees do not feel intimidated, looked down upon, or discriminated just because of their background differences. Thus, MWD is conceived as a reflective construct rather than as a formative construct. An effective diversity management is one that creates and maintains such positive affective diverse workforce climate.

\subsection{Internal Supply Chain Integration}

By nature, organizations are goal-directed social entities; meaning that they are made up of people and groups who work together to achieve some specified ends (Mullins, 2010), designed as deliberately structured and coordinated activity systems, whose operations are linked to the external environment (Daft, 2007). Normally, in the pursuit of achieving the purpose for which they exist, organizations follow a formal process of integrating people, resources, structures, systems, business processes, strategies, functions, etc. as closely as possible (Autry, 1996) with an ultimate goal of improving workflow and optimizing performance (Janićijević, 2013). These descriptions of an organization and its design is not far away from the concept of internal SC integration which relates to the extent to which a firm "structures its organizational strategies, practices and processes into collaborative, synchronized processes, in order to fulfil its customers' requirements and effectively interact with its suppliers" (Flynn, Huo, \& Zhao, 2010). Chang et al. (2016) define internal supply chain integration as "a firm's coordination and collaboration of its organizational information, processes, and behaviours within its boundaries".

After Frohlich and Westbrook's (2001) work on SC integration, many scholars including Fabbe-Costes and Jahre (2008) and Flynn et al. (2010) have made efforts to shape knowledge and research on integrative capabilities within supply chains. Most of these recent scholars have come to believe that in the vertical scope perspective of the supply chain, integration could be pursued either with suppliers, or customers, internally or any combination of these. As argued and supported by Huo's (2012) study, internal integration is a springboard for success in integrating with external supply chain actors; and that firms that fail to develop internal integration could hardly experience higher business performance outcomes. This implies that internal supply chain integration is a form of capability that allows for broader integration across the supply chain.

Given this, and as a search for knowledge to enhance understanding and practice, this study focuses on integration that is pursued internally. We take the position that for the broader supply chain to optimize benefits from managed-workforce diversity; internal SC integration needs to be well developed. While most literature have described and limited internal SC integration to cross-functional integration (Huo et al., 2014; Zailani \& Rajagopal, 2005), we believe that integration at the firm-level could be pursued across the various levels of management within an organization (e.g. aligning strategies, information, processes) across the corporate level to the managerial level and to the operational level. Therefore, this study's measurement of internal SC integration extends beyond the traditional view of cross-functional integration to the more comprehensive view.

\subsection{Business Performance}

Business performance within SC literature has often been related to the positive consequences of SC practices (Anin, Essuman, \& Sarpong, 2016). In most studies, some of the common positive consequences of SC integration have been on operational performance (e.g. efficiency, effectiveness, flexibility, responsiveness, and 
delivery); financial outcomes (e.g. return on investment, return on asset, profitability, and return on sales); marketing performance (e.g. value creation, customer service, and market share); and productivity performance, among others (Chopra \& Meindl 2007; Flynn et al., 2010; Huo, 2012; Cadden, Marshall \& Cao, 2013; Adams et al., 2014; Annan, Boso \& Essuman, 2016). In this study however, in relating managed-workforce diversity (MWD) to internal SC integration, we define and limit business performance to responsiveness performance of the $\mathrm{SC}$ and firm financial performance.

We conceive SC responsiveness as a service performance dimension of the SC and a forerunner to financial performance. The work of Chopra and Meindl (2007) allow us to define responsiveness to mean a SC's ability to swiftly (1) handle wide ranges of quantities demanded, (2) handle a large variety of product demanded, (3) meet short lead times, (4) meet a high service level, and (5) handle service failure. Chopra and Meindl (2007 contend that the best performing SCs are those that are able to achieve the lowest possible cost (i.e. highest efficiency) at a given level of responsiveness, which represents a cost-responsiveness efficient frontier for the SC. We focused on this performance dimension of the SC given the time-and service-based competition that characterizes most SCs today and thus we believe that examining factors that improve or impede it (i.e. SC responsiveness) will be of great value to practitioners in their efforts to sustain their businesses. We also conceive financial performance as a relatively long-term (i.e. less immediate) outcome of MWD and accordingly adapted such items as return on investment, return on asset, overall profitability, growth in profitability, and overall sales/revenue to measure it. Studies on SC integration by various authors (e.g. Huo, 2012; Huo et al., 2014) have captured the financial performance construct with similar indicators.

\section{Hypotheses}

The implicit and explicit orientations and characteristics of employees affect their perceptions of the work environment, their way of thinking, how they relate to other workers, how they handle issues, among others; all of which in turn affect their job behaviours and attitudes (Bano et al., 2013; Stazyk, Davis, \& Liang, 2012). Bogaert and Vloeberghs (2005) discuss four implications of workforce diversity to include: (1) affective consequences (e.g. satisfaction/commitment), (2) communication effects (i.e. communication processes within the organization), (3) cognitive outcomes (e.g. creativity, and innovation), and (4) symbolic effects (e.g.reputation and goodwill). Clearly, the first two and the last two tend to have direct bearings on internal SC integration and business performance outcomes respectively. Although workforce diversity will continue to persist, we believe that firms that are able to bridge the differences and enlarge the communalities among their workforce could obtain such intangible assets as trust and commitment embedded in social structures, relationships, and interactions (Clercq, Dimov, \& Thongpapanl, 2013; Yu, 2013) which are very necessary for enhancing internal SC integration and hence business performance.

MWD could instil a sense of belongingness and loyalty among employees which could be relevant in fostering communication/information sharing, cooperation, group problem solving, and hard work (Bedi et al., 2014).As suggested by the social exchange theory, relationships are built based on norms of reciprocity and mutual benefits (Clercq, Dimov, \& Thongpapanl, 2010; Cropanzano \& Mitchell, 2005) which are relevant for developing relational and integrative capabilities necessary for enhancing business performance (Adams et al., 2014; Miguel \& Brito, 2011). MWD is characterized by a feeling of acceptance and inclusion and a sense of being appreciated or valued. Given this, and based on the assumption that humans are rational and in line with the principle of reciprocity (Cropanzano \& Mitchell, 2005), employees in such work climates are likely to offer in return whatever support their organizations require from them. We therefore expect that:

H1: Managed-workforce diversity will positively affect internal SC integration.

H2: Managed-workforce diversity will positively affect business performance.

Although our earlier arguments and expectations are that MWD will have a direct positive effect on business performance, grasping the mechanisms through which such performance outcomes are manifested could be helpful. We also believe that internal SC integration may better help in understanding the link between these two variables. We admit that having a MWD may not just translate into superior business performance in this competitive environment where rare, inimitable, and unique resources and competences are necessary to at least survive in a given industry (Barney, 1991). In view of this, we follow the submissions offered by authors such as Huo (2012), Chang et al. (2016), and Adams et al. (2014) and argue that integration within SCs could be regarded as a distinct and rare capability that enables firms to realize superior business performance.

However, as presented in our earlier discussions, absence of MWD could restrain internal SC integration and thus we argue that capitalising on the benefits of MWD will allow firms to obtain internal integrative capabilities such as communication, real-time information sharing, seamless business processes, coordinated 
material/product flow \&activity systems, and visibility that their competitors cannot easily imitate. Internal SC integration is necessary to improve workflow and Huo (2012) adds that firms that excel in internal SC integration would be more competitive and enhance performance in the area of delivery, flexibility, and customer service as internal SC integration facilitates co-operation among employees and the alignment of goals, interest, and strategies across all levels of management. Existing literature suggests that internal SC integration brings about positive outcomes including improvements in operational and financial performance as well as reductions in transaction costs (Huo, 2012; Flynn et al., 2010). Flynn et al. (2010) indicated that internal SC integration can help functional areas to leverage each other's resources and capabilities to jointly design products, ensure product quality and reduce duplicated tasks. In light of these, we expect that:

H3: Internal SC integration would positively mediate the direct link between managed- workforce diversity and business performance.

\section{Methods and Results}

\subsection{Measures and instrument Development}

Questionnaires were used to collect data for the study. Guided by Flynn et al.'s (2010) study, we adapted seven items to measure internal SC integration. The items were measured using a 7-point scale, ranging from $1=$ "not at all" to $7=$ "to a largest extent". A review of literature from Cadden et al. (2013), Chopra and Meindl (2007), Huo (2012), and Miguel and Brito (2011), enabled us to come out with six items to measure SC responsiveness using a 7-point scale which ranged from 1 (much worse) to 7 (much better) in relation to key competitor(s). With a 7-point scale (1= "very dissatisfied" to 7= "very satisfied"), five items were adapted from Huo et al. (2014) andKim (2009) to measure financial performance.

In the case of MWD, based on review of extant literature and the operational definition presented in section 2.1, we operationalized it by evaluating the extent to which, in a given organization, employees (1) feel accepted by their colleagues, (2) recognize that their colleagues are equally important; (3) do not look down on the efforts and the presence of others, (4) accept and respect the views of others, and (5) marginalize their differences and identify themselves more with the organization. These measures were retained after a rigorous review by the researchers with the support of individuals in managerial positions who are also executive MBA students of the KNUST school of Business. A scale of 1 (strongly disagree) to 7 (strongly agree) was thus used to measure MWD. The measures that passed the validity test are presented in Table 1.

To control for the potential endogenous effects of firm characteristics on our analysis, we captured three firm-variables: industry-type (manufacturing $=1$; service $=0$ ), age (number of years in the industry), and size (number of full-time employees) as suggested by Antonakis et al. (2010). We perceive that these firm characteristics may influence our hypothesized paths and thus it became necessary to control for them. For instance, Annan et al.'s (2016) study reports results that suggest that these firm characteristics are significantly correlated with both SC integration and financial performance.

\subsection{Design, Sample and Data Collection}

Rather than concentrating on employee-level as the unit of analysis, the study's unit of analysis was organizational-level as the focus was to assess the implications of MWD on the organization's internal SC integration and business performance.A survey design and cross-sectional data were relied on. We focused on service firms from the hospitality and financial sectors and manufacturing firms from the food \& beverages, pharmaceuticals \& chemicals, agri-business, toiletries \& cosmetics, and rubber, plastics \& related firms operating in Ghana. The scarce nature of research on diversity issues within the Ghanaian context was, in part, a drive for the study. Specifically, we sampled the firms from the Ashanti Region of Ghana. The study's geographical context constitutes an emerging ground for firms to embrace ethically and socially responsible organizational policies and SC practices. The springing commercial activities and industrialization in the region (and its geographical position being the centre of the country) has resulted in influx of diverse workforce and which raises concerns for practitioners and researchers. Notably, the region links up the northern and the southern parts of Ghana and also the neighbouring countries with key logistics and SC infrastructure including roads and distribution network systems for business activities (Annan et al., 2016).

In identifying the firms (and also their locations) that fall within the study's context, we relied on two online databases: Yellow Pages Ghana and the Association of Ghana Industry websites. Initially, we tried to make contacts with the firms whose contacts were obtained from these databases through emails but poor response was obtained. To overcome this challenge, we visited the identified firms personally (i.e. face-to-face; in some cases, we were assisted by part-time and executive MBA students of the Kwame Nkrumah University of Science and 
Technology Business School, Kumasi, in reaching out to the firms with letters of introduction to seek the consents of the management of the firms. We were able to do this in two different time phases. The questionnaires were delivered and later collected. In both cases, 170 questionnaires were administered and 126 were retrieved. After preliminary examinations, 117 (79 from phase 1 and 38 from phase 2) were retained as suitable for the study. Those that were rejected were done mainly on the basis of incompleteness and or substantial missing values. While merging the data, we performed t-test to assess whether the data collected from phases 1 and 2 were significantly different or not. We created composite scores for the four focal constructs and used them as the basis for the analysis. The results obtained: MWD (mean difference $=.131 ; \mathrm{t}=.715 ; \mathrm{p}=.476$ ); internal SC integration (mean difference $=-.030 ; \mathrm{t}=-.136 ; \mathrm{p}=.892)$; $\mathrm{SC}$ responsiveness (mean difference $=$ $-.117 ; \mathrm{t}=-.700 ; \mathrm{p}=.486$ ); and financial performance (mean difference $=-.083 ; \mathrm{t}=-.400 ; \mathrm{p}=.690$ ); revealed no significant difference in data collected between the two time phases. $72.6 \%$ and $27.4 \%$ of the firms that participated in the study are respectively from the service industry and manufacturing industry. The average firm age was 19.72 years $(\mathrm{SD}=24.615)$ and size was 174 full-time employees (approx.)( $\mathrm{SD}=270.497)$.

Since the study was at the organizational-level and due to difficulties encountered in reaching out to the firms, we followed existing approach for survey studies of this kind (see for example Huo, 2012). For each firm contacted, a key informant was identified to provide responses for the study. The key informant was supposed to hold at least a managerial position and also have adequate knowledge on issues on under investigation. $30.3 \%$ were CEOs/presidents/vice presidents, $19.3 \%$ were General Managers/Managing Directors, $15.6 \%$ of them were $\mathrm{SC} /$ logistics managers, and 34.9\% were'other' managers in other functional areas. ANOVA conducted across these informant groups showed no significant differences in their responses; given MWD $(\mathrm{F}=.179, \mathrm{p}=.910)$; internal SC integration $(\mathrm{F}=1.189 ; \mathrm{p}=.317)$; $\mathrm{SC}$ responsiveness $(\mathrm{F}=.554, \mathrm{p}=.647)$; and financial performance $(\mathrm{F}=1.415 ; \mathrm{p}=.242)$. The average informant had held his/her current position for 3.85 years $(\mathrm{SD}=2.962)$. Using 7-point scale ( $1=$ strongly disagree; $7=$ strongly agree), we also assessed their level of competence in providing data for the study along four areas which were adapted from Boso, Story, and Cadogan (2013) and the results obtained: knowledge adequacy on issues (Mean=5.89; $\mathrm{SD}=1.120$ ), understanding of items (Mean=5.95; $\mathrm{SD}=1.041$ ), confidence in responses (Mean=6.09; $\mathrm{SD}=.979$ ), and assurance of responses (Mean=6.09; $\mathrm{SD}=1.059)$; and in addition to their level of experience in their positions gave us enough assurance that the responses that were provided better represent the state of affairs regarding the issues we were investigating into in their firms.

\subsection{Measurement Model Analysis}

We first of all employed exploratory factor analysis (using principal component analysis as the estimation method with Varimax for rotation) in SPSS 20 to explore the underlying structure of the data collected on MWD as entirely new measures developed. The analysis extracted one component with Eigen value of 3.193 and explained $63.859 \%$ of the variance. KMO value of .849 and Bartlett's test of sphericity: $\chi^{2}(\mathrm{DF})=245.792(10)$ reached statistically significance level (Tabachnick \& Fidell, 2013). The loadings obtained were: $.751, .863, .728, .836$, and .810 . These measures and those of the other constructs were together subjected to confirmatory factor analysis (CFA) in LISREL 8.5. In CFA, we relied on maximum likelihood estimation method and used covariance matrix as the input (Vieira, 2011). After minor modifications, we followed the steps and recommendations offered by Diamantopoulos and Siguaw, 2000; Hair et al., 2014, and obtained a good model fit to data. The fit indices obtained as shown in Table 1 were within the recommended thresholds suggested by Bagozzi \& Yi (2012). The retained measures, standardized loadings and t-values are shown in Table 1. The positive and significant loadings suggest that convergent validity was attained (Hair et al., 2014). The composite reliability and average variance explained (AVE) values (see Table 1) were all above of .60 and .50 respectively (Bagozzi \& Yi, 2012; Vieira, 2011). All AVEs were larger than the shared variances between constructs; signifying satisfactory discriminant validity (Hair et al., 2014; Vieira, 2011). The scale reliability of the measures was assessed using Cronbach alpha. The results obtained as shown in Table 1 indicate that the scales had good internal consistency, given that all alpha values were above the minimum cut-off point of .70 (Bagozzi \& Yi, 2012). 
Table 1 . Validity and reliability results

\begin{tabular}{|c|c|}
\hline Construct/measures & Loadings (t-values) \\
\hline \multicolumn{2}{|l|}{ Managed-workforce diversity $(\mathrm{CA}=.814 ; \mathrm{CR}=.820 ; \mathrm{AVE}=.535)$} \\
\hline -recognize that their colleagues are equally important & .661 (fixed) \\
\hline -do not look down on the efforts and the presence of others & $.863(7.12)$ \\
\hline -accept and respect the views of others & $.678(6.17)$ \\
\hline -marginalize their differences and identify themselves more with the organisation & $.707(6.38)$ \\
\hline \multicolumn{2}{|l|}{ Internal $\mathrm{SC}$ integration $(\mathrm{CA}=.855 ; \mathrm{CR}=.858 ; \mathrm{AVE}=.602)$} \\
\hline -business information is shared across all levels \& unit areas in this firm & .740 (fixed) \\
\hline -this firm makes use of cross-functional teams and collaboration & $.783(8.07)$ \\
\hline -strategic goals and interest are aligned across all levels \& unit areas & $.863(8.56)$ \\
\hline -all levels \& unit areas are involved in planning and making decisions & $.739(7.62)$ \\
\hline \multicolumn{2}{|l|}{ Supply chain responsiveness $(\mathrm{CA}=.824 ; \mathrm{CR}=.822 ; \mathrm{AVE}=.537)$} \\
\hline -the time it takes to address serve customers or fill customers' orders & .728 (fixed) \\
\hline -the time it takes to adjust processes to meet changing market needs & $.723(6.96)$ \\
\hline -swiftness in resolving process/service failures & $.800(7.51)$ \\
\hline -ability to handle varied customer requirements & $.676(6.55)$ \\
\hline \multicolumn{2}{|l|}{ Financial performance $(\mathrm{CA}=.852 ; \mathrm{CR}=.854 ; \mathrm{AVE}=.595)$} \\
\hline -return on assets & .743 (fixed) \\
\hline -overall profitability & $.868(8.69)$ \\
\hline -growth in profitability & $.752(7.74)$ \\
\hline -overall sales/revenue & $.713(7.34)$ \\
\hline$\chi^{2}(\mathrm{DF})=114.89(98), \chi^{2} / \mathrm{DF}=1.172 ; \mathrm{RMSEA}=.039 ; \mathrm{NNFI}=.957 ; \mathrm{CFI}=.965 ; \mathrm{SRMR}=.058$ & \\
\hline
\end{tabular}

\subsection{Method Bias Assessment}

Given the increasing concerns on the potential bias that could be introduced in studies that deploy self-report instruments such as questionnaires and also the useof single informants to provide data, it became necessary for us to examine the presence of common method bias (CMB) in our study (Podsakoff et al., 2003). However, as part of the design of the study, we employed the following failsafe strategies recommended by Podsakoff et al. (2003) to minimize the presence of CMB. Firstly, different and wide scales were used to measure the constructs. Also, since the questionnaire included several other scales and or constructs (not used in this study), we were able to position the scales in such a way that will make it difficult for obtaining scores whose variances will be highly attributed to the instrument and the design employed. Notwithstanding the above, we also followed previous research statistical approaches (see Boso et el., 2013) to examine the extent to which CMB is present in our data. We estimated three competing models: In Model 1 (method-only), all items were loaded on a single factor: $\chi 2(\mathrm{DF})=1215.23(230), \chi 2 / \mathrm{DF}=5.284 ; \mathrm{RMSEA}=.192 ; \mathrm{NNFI}=.465 ; \mathrm{CFI}=.513 ; \mathrm{SRMR}=.147$. In Model 2 (trait-only), each item was loaded on its specified construct: $\chi 2(\mathrm{DF})=323.47(224), \chi 2 / \mathrm{DF}=1.444$; RMSEA $=.062$; $\mathrm{NNFI}=.903 ; \mathrm{CFI}=.914 ; \mathrm{SRMR}=.060$. Model 3 (method and trait) was modelled to include a single factor linking all items in Model 2: $\chi 2(\mathrm{DF})=254.99(197), \chi 2 / \mathrm{DF}=1.294 ; \mathrm{RMSEA}=.050 ; \mathrm{NNFI}=.925 ; \mathrm{CFI}=.942 ; \mathrm{SRMR}=.053$. After comparing the model fit indices, we found Model 2 and Model 3 to be superior to Model 1 but no substantial differences in the indices for Model 2 and Model 3; which shows that multiple factors better describe our data than a common factor. Accordingly, we conclude that CMB may not be a great threat to our analysis and results.

\subsection{Structural Model Estimation and Hypothesis Evaluation}

Table 2 presents the descriptive statistics and the inter-construct/variable correlations for the study. These results first of all show at least moderate-level/extent scores on all the study's constructs. Most importantly, an average firm agrees that it is able to create and maintain a shared positive affective state where employees do not feel being intimidated, looked down on, or discriminated. With the exception of the link between MWD and financial performance, all other inter-correlations between the study's constructs were significantly positive. 
Table 2.Descriptive and correlation analysis results

\begin{tabular}{|c|c|c|c|c|c|c|c|c|c|}
\hline Variables & 1 & 2 & 3 & 4 & 5 & 6 & 7 & Mean & SD \\
\hline 1. $\quad$ Firm industry-type $^{1}$ & & & & & & & & & \\
\hline 2. $\quad$ Firm age $\mathrm{e}^{2}$ & .106 & & & & & & & & \\
\hline 3. $\quad$ Firm size ${ }^{2}$ & .032 & $.747^{* *}$ & & & & & & & \\
\hline Managed- workforce diversity & .018 & .107 & .035 & & & & & 5.04 & .930 \\
\hline 5. Internal SC integration & .091 & $.189^{*}$ & $.197^{*}$ & $.388^{* *}$ & & & & 5.35 & 1.130 \\
\hline 6. SC responsiveness & -.143 & $.225^{*}$ & .180 & $.324^{* *}$ & $.434^{* *}$ & & & 4.91 & .844 \\
\hline 7. Financial performance & .174 & .083 & .167 & .081 & $.464^{* *}$ & $.184^{*}$ & - & 4.61 & 1.053 \\
\hline
\end{tabular}

Notes: ${ }^{1}$ natural $\log$ form; ${ }^{1}$ dummy variable [Industry: $1=$ manufacturing, $0=$ service]; ${ }^{*} \mathrm{p}<.05$ (2-tailed); ${ }^{* *} \mathrm{p}<.01$ (2-tailed).

To test the study's hypotheses, we used structural equation modelling (SEM) technique in LISREL 8.5. We estimated two models. In Model 1, we freely estimated the effects of the control variables while constraining the hypothesized paths to zero. In Model 2, all paths were freely estimated. Referring from Table 3, the fit indices of Model 2 were superior to those of Model 1. From the results obtained in Model 2, the study's hypotheses were evaluated as follows:

As shown in Table 3, significant statistical support was obtained for H1; which stated that MWD will positively affect internal SC integration. H2 posited that MWD will positively affect business performance. The results obtained (see Table 3) did not support H2. Only the path from MWD to SC responsiveness was positive, though not statically significant. H3stated that internal SC integration would positively mediate the positive effect link between MWD and business performance. The results obtained only seem to provide a partial support for H3. First of all, the path from MWD to financial performance was negative (although not significant), which is contrary to our expectation. Only that of MWD to SC responsiveness was positive. And also, the indirect effects through internal SC integration were positive. Thus, the results only suggest that internal SC integration has positive mediating effects in the direct link between MWD on SC responsiveness. To robustly assess this positive mediation result, we followed a SEM-based technique employed by $\mathrm{Lu}$ et al. (2010). We focused only on the structural linkages among MWD, internal SC integration, and SC responsiveness and also controlled for the effects of firm industry-type, age, and size on both internal SC integration and SC responsiveness and estimated several competing models through sequential Chi-square test of difference.

Table 3.Structural model results

\begin{tabular}{|c|c|c|c|c|c|c|}
\hline \multirow[b]{3}{*}{ Variables } & \multicolumn{6}{|c|}{ Standardized estimates } \\
\hline & \multicolumn{3}{|l|}{ Model $1^{\dagger}$} & \multicolumn{3}{|l|}{ Model 2} \\
\hline & ISCI & SCR & $\mathrm{FP}$ & ISCI & SCR & $\mathrm{FP}$ \\
\hline \multicolumn{7}{|l|}{ Control paths } \\
\hline Firm industry & $.09(.87)$ & $-.18(-1.81)$ & $.22(2.19)^{*}$ & $.08(.94)$ & $-.22(-2.48)^{*}$ & $.12(1.32)$ \\
\hline Firm age & $.09(.67)$ & $.26(1.70)$ & $-.19(-1.25)$ & $.02(.12)$ & $.17(1.28)$ & $-.15(-1.072)$ \\
\hline Firm size & $.15(.99)$ & $.01(.09)$ & $.25(1.71)$ & $.19(1.39)$ & $-.03(-.21)$ & $.15(1.12)$ \\
\hline SC responsiveness & & & $.25(2.14)^{*}$ & & & $-.01(-.08)$ \\
\hline \multicolumn{7}{|l|}{ Hypothesized paths } \\
\hline Managed-workforce diversity & & & & $.42(4.37)^{* *}$ & $.14(1.44)$ & $-.16(-1.56)$ \\
\hline ISCI & & & & & $.47(3.83)^{* *}$ & $.58(3.93)^{* *}$ \\
\hline$\chi^{2} / \mathrm{DF}$ & \multicolumn{3}{|c|}{$183.00 / 92=1.989$} & \multicolumn{3}{|c|}{$117.17 / 87=1.347$} \\
\hline RMSEA & \multicolumn{3}{|l|}{.092} & \multicolumn{3}{|l|}{.055} \\
\hline NNFI & \multicolumn{3}{|l|}{.816} & \multicolumn{3}{|l|}{.924} \\
\hline CFI & \multicolumn{3}{|l|}{.859} & \multicolumn{3}{|l|}{.945} \\
\hline SRMR & \multicolumn{3}{|l|}{.165} & \multicolumn{3}{|l|}{.059} \\
\hline $\mathrm{R}^{2}$ & $5.9 \%$ & $9.3 \%$ & $11.5 \%$ & $23.5 \%$ & $37.9 \%$ & $32.4 \%$ \\
\hline
\end{tabular}

Notes: ISCI=internal SC integration; $\mathrm{SCR}=\mathrm{SC}$ responsiveness; FP = financial performance; t-values are in the parenthesis; ${ }^{\dagger}$ hypothesized paths constrained to zero; ${ }^{*} \mathrm{p}<.05$ (2-tailed); ${ }^{* *} \mathrm{p}<.01$ (2-tailed). 
We first of all estimated a baseline model (i.e. full mediation, including the controls), which did not have the path of the precursor construct (MWD) link to the criterion (SC responsiveness). The results obtained as displayed in Table 4 show a good fit to data. Following this, we restricted the indirect effect paths through internal SC integration to zero. This resulted in a significant change in Chi-square and poor model fit indices which suggest that these paths were important (see Table 4). Next, we estimated and compared a partial mediation model to the full mediation model. This did not result in significant change in Chi-square or improvement in the fit indices and thus suggested that the full mediation equally fit the data well. To rule out further alternative explanations, we estimated a direct effect model (i.e. constraining the path linking MWD and internal SC integration to zero) and a non-mediation model (i.e. constraining the path linking internal SC integration and SC responsiveness to zero). Both models resulted in significant changes in Chi-square over the partial mediation model and worsened model fit indices. Between the partial and full mediation models, we settled on the full mediation model as it represented a more parsimonious model structure and also provided equally good fit to data.

Table 4. Mediation analysis (competing models)

\begin{tabular}{llllllll}
\hline Model & $\chi^{2}(\mathrm{DF})$ & $\chi^{2} / \mathrm{DF}$ & $\Delta \chi^{2}$ & RMSEA & NNFI & CFI & SRMR \\
\hline Baseline (b) & $70.04(44)$ & 1.592 & - & .071 & .910 & .940 & .062 \\
Model 1 & $120.00(46)$ & 2.609 & $\Delta \chi^{2}{ }_{(\mathrm{b}, \mathrm{m} 1)}=49.96^{*}$ & .118 & .791 & .854 & .166 \\
Model 2 & $68.40(43)$ & 1.591 & $\Delta \chi^{2}(\mathrm{~b}, \mathrm{~m} 2)=1.64$ & .071 & .910 & .941 & .060 \\
Model 3 & $86.41(44)$ & 1.964 & $\Delta \chi^{2}(\mathrm{~m} 2, \mathrm{~m} 3)=18.01^{*}$ & .091 & .858 & .905 & .100 \\
Model 4 & $83.61(44)$ & 1.900 & $\Delta \chi^{2}(\mathrm{~m} 2, \mathrm{~m} 4)=15.21^{*}$ & .088 & .867 & .912 & .107 \\
\hline
\end{tabular}

Notes:

1. Baseline model (b): full mediation (i.e. no direct path from managed-workforce diversity to $\mathrm{SC}$ responsiveness)

2. Model 1: indirect effect paths (i.e. paths from managed-workforce diversity through internal SC integration to SC responsiveness) were constrained to zero

3. Model 2: partial mediation (i.e. baseline model plus direct path from managed-workforce diversity to SC responsiveness estimated)

4. Model 4: direct effect model (i.e. path managed-workforce diversity to internal SC integration was constrained to zero)

5. Model 5: non-mediation model (i.e. path from internal SC integration to SC responsiveness was constrained to zero)

6. $\quad{ }^{*} \mathrm{p}<.01$

\section{Discussions}

With a principal focus on finding out whether (or not) it is worth managing workforce diversity, this study examined the implications of MWD on internal SC integration and performance. In relation to this objective, the results obtained from the study's context highlight several theoretical contributions and managerial implications which we discuss as follows:

\subsection{Theoretical Contributions}

To begin, following the recent shift of attention on taking a strategic lens in managing workforce diversity (Munjuri, 2012), our study conceptualized the term "managed-workforce diversity" (MWD), developed and validated its measures, and argued that research should move from just examining the consequences of "workforce diversity"to the management aspect of it that creates a shared positive affective climate where workforce do not feel intimated, looked down on, or discriminated. Accordingly, the study found some support for the business benefits of this construct.

To better understand the implications of MWD, this study first of all followed a research by Richard et al. (2015) in which they emphasized that knowing when the benefits of diversity will be accrued (if any) is important. Drawing on their line of enquiry, this study makes a contribution by exploring a 'more immediate' consequence of managed-workforce diversity (i.e. internal SC integration), and then an inter-mediate consequence (SC responsiveness), and a relatively long-term consequence (financial performance). Given this, we were able to examine when the direct benefits of MWD could be accrued. The results obtained indicate that, MWD is likely to be beneficial in enhancing internal SC integration, and then, SC responsiveness. The results further suggest that MWD is a considerable antecedent of internal SC integration which cannot just be ignored. In diverse workforce environment, without attaining MWD, it will be difficult for firm to get the trust, commitment, loyalty, 
and cooperation among of employees (Madera et al., 2013; Roberge \& van Dick, 2010; Bedi et al., 2014) necessary for integrating their internal SC activities and or operations (Adams et al., 2014; Miguel and Brito, 2011). In terms of the link between MWD and business performance, we did not find statistically significant associations. This finding contradicts our initial arguments and expectation. This finding suggests that even having MWD does not necessarily result in increased financial performance. To effectively implement management policies and programs in order to realize MWD, firms need to pump-in adequate financial resources and as such, financial benefits obtained from diversity management may be off-set by the monetary costs necessary to at least sustain it.

Further, to grasp the mechanisms through which managed-workforce diversity affects performance (SC responsiveness and financial performance), the study argued that internal SC integration is a form of firm capability (Flynn et al., 2010; Huo, 2012) necessary for channelling the effects of managed-workforce diversity on performance. The results obtained in the study yielded a partial support for this argument. The study found that the positive effect of MWD on SC responsiveness is transmitted via internal SC integration. This finding points out internal SC integration as very instrumental for firms to successfully translate dormant resources (e.g. trust, loyalty, commitment) embedded in MWD into real benefits such as the ability to respond swiftly to the needs of customers in this time-based competitive era.

The study also makes relevant contribution by adopting an inter-disciplinary perspective and broadening the fit between human resource (HR) practices (workforce diversity management) and SC practices (internal SC integration). Notably, empirical research on HR practices in SCs is scarce and relevant issues are still underexplored (Huo et al., 2015). While other HR and organizational issues such as top-management support (Zhao et al., 2015), employee skills, incentives, participation (Huo et al., 2015), and organizational culture (Cao et al., 2015; Cadden et al., 2013) and their impacts on SC integration have been explored, research on workforce diversity and MWD and their implications on SC integration has not received empirical consideration.

Also, the study makes a contribution by addressing the context gap issue raised by recent authors (e.g. Kaufmann \& Wagner, 2017; Singal \& Gerde, 2015; Richard et al., 2015). Available literature suggests that most of the discussions and studies on diversity have been staged in advanced economies, particularly, in the US and Europe (Podsiadlowski et al., 2013). Evidence from countries in the 'bottom-of-the-pyramid' (BOP), particularly, Africa, is largely lacking. Generally, the institutional environment of BOP nations runs in sharp contrast with that of advanced ones on several issues. For instance, the unique institutional environment (e.g. culture, norms, values, and government policies and regulations) may have different implications on diversity programs and their successes.

\subsection{Managerial Implications}

The findings of this study provide clear implications for management in the research context in their efforts to embrace workforce diversity. The study started by clarifying that embracing diversity just for the purposes of meeting regulatory requirements or as a corporate social responsibility is not enough, but rather the management of it is what matters (Henry \& Evans, 2007; Munjuri, 2012). The study acknowledged that workforce diversity present challenges as well as opportunities for firms (Bedi et al., 2014). As Roberge and van Dick (2010) put it, workforce diversity in itself implies heterogeneity in teams. Heterogeneity can reduce cohesiveness among workforce, and result in misunderstanding and conflicts, as well as role ambiguity (Madera et al., 2013) which may have negative consequences on internal SC integration, the responsiveness of a firm's SC in addressing market needs, and financial outcomes. Therefore, having a MWD could go a long way to benefit firms (Bedi et al., 2014; Gee \& Norton, 1999).

Per the results of this study, we postulate that inability to create MWD could result in lower organizational benefits; particularly, in the areas of integrating people and workflow at the focal firm-level and also the ability of a firm's SC to responsively address market needs. We also postulate that a higher level of MWD is likely to be associated with higher levels of these benefits. Managers therefore ought to be aware that while internal SC integration is the key to unlock superior integrative capabilities across parties within the SC to enhance business performance (Huo, 2012), without effective harmonisation of the differences in employees' orientations and strengthening their similarities at each focal firm-level, it could be very difficult for their SCs to realize sustained integration. Generally, people are willing to engage in integrative practices such as cooperation, information sharing, and coordinating of efforts when they feel being accepted and valued by others and not looked down upon just because of their different orientations or backgrounds. From the findings of the study, we believe that work environments that are characterized by MWD could obtain commitment, trust, and loyalty (necessary for enhancing internal integration) from their employees as they will be more likely to be satisfied with the treatment 
they get at the workplace and also find the work environment as an alternate 'home'.

Although it is less discussed in extant literature, we consider most supply chains (SCs) to be largely characterized by human elements which require effective management. Since it is organizations that largely make up SCs and these organizations and their processes are not just mechanistic but also facets of social structures and processes (Mullins, 2010), the role of people management is key for successful implementation of SC practices (Bharthvajan, 2014). Against this, the evidence obtained in this study enables us to suggest that managers focus on developing a unified workforce from the perspective of workforce diversity management. We believe that irrespective of how sound policies, strategies, machinery, etc. are, the success of the organization greatly lies in the manner in which its employees combine other resources and execute them. Employees and their skills and expertise in this regard could be regarded as operant resources (Adam et al. 2014) that every SC requires in order to effectively exploit capabilities rooted in other resources within the SC to their advantage. We accordingly want to emphasize that the lack of effectiveness in creating a pool of diverse workforce could result in difficulties in aligning the structures, systems, strategies, processes, etc. of the organization. Conflicts and role ambiguity which usually result from differences in background characteristics of employees (Madera et al., 2013; Roberge \& van Dick, 2010) could restrain integration initiatives at the focal firm-level and at the external streams of the SC. It should be recognized that, while other capabilities necessary for developing SCs (e.g. information technology) could be imitated, that which is embedded in MWD (e.g. trust and commitment) are rare and could hardly be imitated. Therefore we believe that obtaining these capabilities through MWD could provide avenues of realising competitive advantage.

Notwithstanding all the above, the findings of the study also seem to caution practitioners on the likely financial implications of workforce diversity management. While we find MWD to be likely beneficial in the terms of improving SC responsiveness via internal SC integration, it may also affect financial positions of organizations in the study's context negatively. Our findings tend to indicate that pursuing MWD could result in decreasing financial outcomes. Based on this, management should be aware that sound financial anchors may be necessary for pursuing and sustaining workforce diversity management and that lack of it could eat into financial outcomes that might have been earned while pursuing such initiatives. We perceive that this relatively long term effect of MWD could be moderated by internal structures that allow firms to have control over cost of implementing workforce diversity management programmes thereby optimizing any potential financial outcomes.

\section{Conclusion and Future Research Directions}

This study argued and showed that having MWD could prove beneficial for integrating SC elements at the focal firm-level. The results suggest that performance outcomes in terms of SC responsiveness resulting from MWD could better be transmitted via internal SC integration. Lastly, the study reveals that creating MWD may not have a direct long-term financial effect. Beyond these, the study opens up several avenues for rich insights to be gained through further research. Advancing this study, we acknowledge our limitations and offer directions to guide researchers seeking to broaden knowledge on the antecedents, consequences, and boundary conditions of diversity and diversity management within the SC literature. Given the prime research question that needed to be addressed, the study did not focus on exploring factors that are exogenous to MWD. Also, literature reviewed shows inadequate empirical examination on the nature of workforce diversity, its specific practices, policies and programs within the Sub-Saharan African region, and particularly, within the Ghanaian context. We acknowledge that investigating into how firms within the operating context actually undertake workforce diversity management could yield valuable insights. In this line, we suggest that future studies investigate into the policies, programs, and practices deployed by organizations in managing workforce diversity as their success and any potential benefits to be derived could be contingent upon these factors. As Jayne and Dipboye (2004) put it, the success of diversity programs is contingent on goals and or policies and how they are framed and communicated and also on feedback systems. Madera (2013), also notes that effective diversity practices are formal, and that written guidelines and policies are necessary to enhance diversity implementation. Future studies could explore the antecedent and moderating effects of these variables on workforce diversity management and MWD.

Further, we admit that managing diversity at the firm-level alone may not necessarily be sufficient for the benefits of the broader SC. While we argue that each focal firm within the network could benefit from managing its diverse workforce, we also believe that aligning such initiatives or efforts with that of members at either streams could be beneficial for an extended SC integration. In this line, we recommend that further studies map out for diversity that is pursued within firms and also at both the external streams of the SC (i.e. supplier-market diversity and customer-market diversity). Given this, future studies should profile various configurations of diversity management across the $\mathrm{SC}$ and examine which profile optimizes performance. 


\section{References}

Adams, F. G., Jr. Richey, R. G., Autry, C. W., Morgan, T. R., \& Gabler, C. B. (2014). Supply chain collaboration, integration, and relational technology: How complex operant resources increase performance outcomes. Journal of Business Logistics, 35(4), 299-317. https://doi.org/10.1111/jbl.12074

Anin, E. K., Essuman, D., \& Sarpong, K. O. (2016). The influence of governance mechanism on supply chain performance in developing economies: Insights from Ghana. International Journal of Business and Management, 11(4), 252-264. https://doi.org/10.5539/ijbm.v11n4p252

Annan, J., Boso, N., \& Essuman, D. (2016).Investigating the path from supply chain integration to business performance: Evidence from a Sub-Saharan African economy. International Journal of Business and Management, 11(6), 225-240. https://doi.org/10.5539/ijbm.v11n6p225

Antonakis, J., Bendahan, S., Jacquart, P., \& Lalive, R. (2010). Onmaking causal claims: A review and recommendations.The Leadership Quarterly, 21(6), 1086-1120. https://doi.org/10.1016/j.leaqua.2010.10.010

Autry, H. R. (1996). What is organisation design? http://www.inovus.com/organiza.htm/

Bagozzi, P. R., \& Yi, Y. (2012). Specification, evaluation, and interpretation of structural equation models. Academy of Marketing Science, 40(1), 8-34. https://doi.org/10.1007/s11747-011-0278-x

Bano, S., Fahad, M., Khan, A., \& Butt, N. A. (2013).Analysis of workforce diversity, commitment of employee's and its effects on organizational performance: Corporate sector in Islamabad Pakistan. International Review of Basic and Applied Sciences, 1(3), 98-106.

Barney, J. (1991). Firm resources and sustained competitive advantage. Journal of Management, 17(1), 99-120. https://doi.org/10.1177/014920639101700108

Bedi, P., Lakra, P., \& Gupta, E. (2014). Workforce diversity management: Biggest challenge or opportunity for 21 st century organizations. Journal of Business and Management, 16(4), 102-107.

Bogaert, S., \& Vloeberghs, D. (2005). Differentiated and individualized personnel management: Diversity management in Belgium. European Management Journal, 23(4), 483-493. https://doi.org/10.1016/j.emj.2005.06.001

Boso, N., Story, V. M., \& Cadogan, J. W. (2013). Entrepreneurial orientation, market orientation, network ties, and performance: Study of entrepreneurial firms in a developing economy. Journal of Business Venturing, 28, 708-727. https://doi.org/10.1016/j.jbusvent.2013.04.001

Cadden, T., Marshall, D., \& Cao, G. (2013). Opposites attract: Organisational culture and supply chain performance. Supply Chain Management: An International Journal, 18(1), 86-103. https://doi.org/10.1108/13598541311293203

Cao, Z., Huo, B., Li, Y., \& Zhao, X. (2015). The impact of organizational culture on supply chain integration: A contingency and configuration approach. Supply Chain Management: An International Journal, 20(1), 24-41. https://doi.org/10.1108/SCM-11-2013-0426

Chang, W., Ellinger, A. E., Kim, K. K., \&Franke, G. R. (2016). Supply chain integration and firm financial performance: A meta-analysis of positional advantage mediation and moderating factors. European Management Journal, 34(3), 282-295. https://doi.org/10.1016/j.emj.2015.11.008

Charted Institute of Purchasing and Supply. (2009). Supplier diversity. CIPS Knowledge Works, 44(1), 1-5.

Chopra, S., \& Meindl, P. (2007). Supply chain management, strategy, planning \& operation (3rd ed.). New Jersey: Pearson Education Inc. https://doi.org/10.1007/978-3-8349-9320-5_22

Clercq, D. D., Dimov, D., \&Thongpapanl, N. T. (2010). The moderating impact of internal social exchange processes on the entrepreneurial orientation - performance relationship. Journal of Business Venturing, 25(1), 87-103. https://doi.org/10.1016/j.jbusvent.2009.01.004

Clercq, D. D., Dimov, D., \&Thongpapanl, N. T. (2013). Organizational social capital, formalization, and internal knowledge sharing in entrepreneurial orientation formation. Entrepreneurship Theory and Practice, 37(3), 505-537. https://doi.org/10.1111/etap.12021

Cropanzano, R., \& Mitchell, M. S. (2005). Social exchange theory: an interdisciplinary review. Journal of Management, 31(6), 874-900. https://doi.org/10.1177/0149206305279602

Daft, R. L. (2007). Organisation theory and design (9th ed.). Mason: Thomson South Western. 
De Jong, G., \& Van Houten, J. (2014). The impact of MNE cultural diversity on the internationalization-performance relationship: Theory and evidence from European multinational enterprises. International Business Review, 23(1), 313-326. https://doi.org/10.1016/j.ibusrev.2013.05.005

Fabbe-Costes, N., \& Jahre, M. (2008). Supply chain integration and performance: A review of the evidence. The $\begin{array}{lllr}\text { International Journal of Logistics } & \text { Management 19(2), }\end{array}$ https://doi.org/10.1108/09574090810895933

Flynn, B.B., Huo, B., \& Zhao, X. (2010). The impact of supply chain integration on performance: A contingency and configuration approach. International Journal of Operations \& Production Management, 28, 58-71. https://doi.org/10.1016/j.jom.2009.06.001

Frohlich, M. T., \& Westbrook, R. (2001). Arcs of integration: An international study of supply chain strategies. Journal of Operations Management, 19(2), 185-200. https://doi.org/10.1016/S0272-6963(00)00055-3

Gee, M. V., \& Norton, S. M. (1999). The confluence of gender and culture: Sexual harassment in the international arena. Management Decision, 37(5), 417-423. https://doi.org/10.1108/00251749910274199

Gelfand, M. J., Nishii, L., Raver, J., \& Schneider, B. (2005). Discrimination in organizations: A systems perspective. In Dipboye, R., Clella, A. (Eds.), Psychological and Organizational Bases of Discrimination at Work. Jossey Bass, New York, pp. 89-116.

Hair Jr., F. J., Black, C. W., Babin, J. B., \&Anderson, E. R. (2014). Multivariate data analysis (7th ed.). Edinburgh Gate: Pearson Education Inc.

Henry, O., \& Evans, A. J. (2007). Critical review of literature on workforce diversity. African Journal of Business Management, 1(4), 72-76.

Huo, B. (2012). The impact of supply chain integration on company performance: An organizational capability perspective. Supply Chain Management: An International Journal, 17(6), 596-610. https://doi.org/10.1108/13598541211269210

Huo, B., Han, Z., Chen, H., \& Zhao, X. (2015). The effect of high-involvement human resource management practices on supply chain integration. International Journal of Physical Distribution \& Logtistics Management, 45(8), 716-746. https://doi.org/10.1108/IJPDLM-05-2014-0112

Huo, B., Qi, Y., Wang, Z., \& Zhao, X. (2014). The impact of supply chain integration on firm performance: The moderating role of competitive strategy. Supply Chain Management: An International Journal, 19(4), 369-384. https://doi.org/10.1108/SCM-03-2013-0096

Huo, Y., Jiang, X., Jia, F., \& Li, B. (2009). A framework and key techniques for supply chain integration. In Y. Huo, \& F. Jia (Eds.), Supply chain: the way to flat organisation (pp. 215-223). Vienna: I-Tech. https://doi.org/10.5772/6661

Jackson, S. E., Joshi, A., \&Erhardt, N. L. (2003). Research on team and organizational diversity: Swot analysis and implications. Journal of Management, 29(6), 801-830. https://doi.org/10.1016/S0149-2063(03)00080-1

Janićijević, N. (2013). The mutual impact of organizational culture and structure. Economic Annals, 58(198), 35-60. https://doi.org/10.2298/EKA1398035J

Jayne, M. E. A., \& Dipboye, R. L. (2004). Leveraging diversity to improve business performance: Research findings and recommendations for organizations. Human Resource Management, 43(4), 409-424. https://doi.org/10.1002/hrm.20033

Kaufmann, L., \& Wagner, C. M. (2017). Affective diversity and emotional intelligence in cross-functional sourcing teams. Journal of Purchasing and Supply Management, In Press (2017). https://doi.org/10.1016/j.pursup.2016.07.004

Keil, M., Amershi, B., Holmes, S., Jablonski, H., Lüthi, E., Matoba, K., \& Von Unruh, K. (2007). Training manual for diversity management. Bruxelles: European Commission.

Kim, S. W. (2009). An investigation on the direct and indirect effect of supply chain integration on firm performance. International Journal of Production Economics, 119(2), 328-346. https://doi.org/10.1016/j.ijpe.2009.03.007

Konrad, A. M. (2003). Special issue introduction: Defining the domain of work-place diversity scholarship. Group \& Organisation Management, 28(1), 4-17. https://doi.org/10.1177/1059601102250013 
Lu, Y., Zhou, L., Bruton, G., \& Li, W. (2010). Capabilities as a mediator linking resources and the international performance of entrepreneurial firms in an emerging economy. Journal of International Business Studies, 41, 419-436. https://doi.org/10.1057/jibs.2009.73

Madera, J. M., Dawson, M., \& Neal, J. A. (2013). Hotel managers' perceived diversity climate and job satisfaction: The mediating effects of role ambiguity and conflict. International Journal of Hospitality Management, 35, 28-34. https://doi.org/10.1016/j.ijhm.2013.05.001

Miguel, L. P. D. S., and Brito, A. L. L. (2011). Supply chain management measurement and its influence on operational performance. Journal of Operations and Supply Chain Management, 4(2), 56-70.

Mullins, J. L. (2010). Management \& organisational behavior (9th ed.). Edinburge Gate: Pearson Education Inc.

Munjuri, M. G. (2012). Workforce diversity management and employee performance in the banking sector in Kenya. DBA Africa Management Review, 3(1), 1-21.

Patrick, H. A., \& Kumar, V. R. (2012). Managing workplace diversity: Issues and challenges. Sage Open, 2(2), 1-5. https://doi.org/10.1177/2158244012444615

Podsakoff, P. M., MacKenzie, S. B., Lee, J. Y., \& Podsakoff, N. P. (2003). Common method biases in behavioral research: A critical review of the literature and recommended remedies. The Journal of Applied Psychology, 88(5), 879-903. https://doi.org/10.1037/0021-9010.88.5.879

Podsiadlowskia, A., Gröschkeb, D., Koglera, M., Springera, C., \& Van der Zeec, K. (2013). Managing a culturally diverse workforce: Diversity perspectives in organizations. International Journal of Intercultural Relations, 37, 159-175. https://doi.org/10.1016/j.ijintrel.2012.09.001

Point, S., \& Singh, V. (2003). Defining and Dimensionalising Diversity: Evidence from Corporate Websites across Europe. European Management Journal, 21(6), 750-761. https://doi.org/10.1016/j.emj.2003.09.015

Prajogo, D., \& Olhager, J. (2012). Supply chain integration and performance: The effects of long-term relationships, information technology and sharing, and logistics integration. International Journal of Production Economics, 135(1), 514-522. https://doi.org/10.1016/j.ijpe.2011.09.001

Richard, O. C., Su, W., Peng, M. W., \& Miller, C. D. (2015). Do external diversity practices boost focal firm performance? The case of supplier diversity. The International Journal of Human Resource Management, 26(17), 2227-2247. https://doi.org/10.1080/09585192.2014.985324

Roberge, M. É., \& Van Dick, R. (2010). Review Recognizing the benefits of diversity: When and how does diversity increase group performance? Human Resource Management Review, 20(4), 295-308. https://doi.org/10.1016/j.hrmr.2009.09.002

Rosenzweig, P. (1998). Managing the new global workforce: Fostering diversity, forging consistency. European Management Journal, 16(6), 644-652. https://doi.org/10.1016/S0263-2373(98)00041-3

Singal, M., \& Gerde, V.W. (2015).Is diversity management related to financial performance in family firms? Family Business Review, 28(3), 243-259. https://doi.org/10.1177/0894486514566012

Stazyk, E. C., Davis, R.S. J., \& Liang, J. (2012). Examining the links between workforce diversity, organisational goal clarity, and job satisfaction. In Annual Meeting and Exhibition of the American Political Science Association (2012). http://papers.ssrn.com/sol3/papers.cfm?abstract_id=2107330. Accessed 29.12.16.

Süß, S., \& Kleiner, M. (2008). Dissemination of diversity management in Germany: A new institutionalist approach. European Management Journal, 26(1), 35-47. https://doi.org/10.1016/j.emj.2007.10.003

Tabachnick, G.B., \& Fidell, S.L. (2013).Using multivariate statistics.(6th ed.). New Jersey: Pearson Education Inc.

Vieira, A. L. (2011). Interactive LISREL in practice: getting started with a SIMPLIS approach. New York: Springer. https://doi.org/10.1007/978-3-642-18044-6

Yu, S. H. (2013). Social capital, absorptive capability, and firm innovation. Technological Forecasting \& Social Change, 80(7), 1261-1270. https://doi.org/10.1016/j.techfore.2012.12.005

Zailani, S., \&Rajagopal, P. (2005). Supply chain integration and performance: US versus East Asian Companies.Supply Chain Management: An International Journal, 10(5), 379-393. https://doi.org/10.1108/13598540510624205 
Zhao, G., Feng, T., \& Wang, D. (2015).Is more supply chain integration always beneficial to financial performance? Industrial Marketing https://doi.org/10.1016/j.indmarman.2015.02.015

\section{Copyrights}

Copyright for this article is retained by the author(s), with first publication rights granted to the journal.

This is an open-access article distributed under the terms and conditions of the Creative Commons Attribution license (http://creativecommons.org/licenses/by/4.0/). 